\title{
Capacity Building Strategies: Can they promote Socially Just Strategic Intervention in Urban Governance?
}

\author{
Eulanie Ouseley-Torrezao \\ Coordinator, Division of Social Sciences, University of Guyana Berbice Campus \\ Tain, Corentyne, Berbice \\ Tel: 1-592-337-2309Ｅ-mail: eulanie.ouseley@uog.edu.gy
}

Received: June 21, 2013 Accepted: July 12, $2013 \quad$ DOI: 10.5296/jpag.v3i3.3882

\begin{abstract}
This paper analyses Capacity Building Interventions through three areas Human Resource Development, Organizational Development and Institutional Reform and explores a tool that promotes socially just capacity building interventions at the municipal level.
\end{abstract}

Keywords: Capacity Building, Socially Just Interventions, Governance, Human Resource Development, Organizational Development, Institutional Reform, Gender 


\section{Introduction}

\subsection{Social Justice}

Defining the concept 'social justice' can prove to be a very difficult task as it is left to the individual to determine what he or she considers to be 'socially just.' However, in my opinion, the best attempt at defining the concept is the one done by Young (1990:15) where she states that social justice is "the elimination of institutionalized domination and oppression" while Miller (2000) goes on to expand this by pinpointing that social justice entails full participation of all actors in society and the 'just distribution of society's benefits and burdens'. Implicit in Miller's definition is the suggestion that the institution is responsible for ensuring that participation and distribution is equitable while it is explicit in Young's terms that the 'institution' can be directly linked to practices of injustice. Therefore, eliminating this 'domination and oppression' and guaranteeing that all citizens enjoy fair participation and distribution entails widespread institutional reform.

\subsection{Strategic Intervention}

Secondly, 'strategic intervention' as portrayed by Levy (2007) is "a form of purposeful collective action that will expand the capacity for human agency and the opportunities for change within structures and institutions, i.e., expand the room for maneuver by creating synergy between different actors and having a multiplier effect through promoting transformation." What earlier theories have failed to stress but is rightly acknowledged by Levy is the significance of promoting sustainable development through effective and efficient human resources, organizations, and institutions. Therefore, socially just strategic intervention is necessary for effective urban governance.

\subsection{Urban Governance}

But what is meant by 'urban governance' and why is this concept so meaningful in the general debate about capacity-building? To speak about 'government' interchangeably with 'governance' is a huge mistake, since, as highlighted by Levy (2007) and Miller (2000), government is only one of the many actors in governance. The UNDP supports this view by stating that governance is "the exercise of economic, political and administrative authority to manage a country's affairs at all levels. It compromises mechanisms, processes and institutions through which citizens and groups articulate their obligations and exercise legal rights; meet their obligations and mediate their differences" (1997: 2-3). The role of the many actors in governance is obviously identified in this definition but is not as clearly stated as it is in the definition given in a 1995 study by McCarney, Halfani and Rodriguez (cited in McCarney, 1996:4) as "the relationship between civil society and the state, between rulers and the ruled, the government and the governed." So, urban governance is about building relationships in the management of the city. It can be easily interpreted that unless strategic intervention is socially just it can threaten this 'relationship' among actors, and hinder their respective roles.

\section{Capacity Building Strategies}

Now that we understand the concepts, how can we ensure that there is socially just strategic 
intervention in urban governance? Simply put, through effective capacity-building. During my earlier studies I have also reiterated the mistake made by many people. That is, to assume that capacity building is solely about training. While, in my opinion, education and training is the most important factors of capacity-building, it also encompasses other dimensions (see Appendix 1). According to Grindle (1997), in addition to developing human resources, these dimensions also consists of strengthening organizations and reforming institutional and legal frameworks. Grindle believes that "capacity building is intended to encompass a variety of strategies that have to do with increasing the efficiency, effectiveness, and responsiveness of government performance." To contradict Grindle's theory, urban governance (as discussed above) does not deal with government alone, so capacity building, while its main focus should be on the public sector, it should also include the private sector, NGOs, CBOs and other members of civil society. To further emphasize my point is the following declaration:

"Specifically, capacity building encompasses the country's human, scientific, technological, organizational, institutional and resource capabilities. A fundamental goal of capacity building is to enhance the ability to evaluate and address the crucial questions related to policy choices and modes of implementation among development options, based on an understanding of environment potentials and limits and of needs perceived by the people of the country concerned".

\section{Capacity Building - Agenda 21's definition}

In other words, in addition to involving all actors in the strategies that aim to develop human resources, strengthen organizations and reform institutions, Agenda 21 has identified a very important and often excluded fourth element that has a major impact on capacity building an understanding of the external environment - economic, political and social and cultural 'based on the limits and needs of the people' or as expressed by Levy (1998) the 'women's and men's experiences and their reflective interpretation of reality."

But the big question is, what do these 'strategies' entail and how effective are they in ensuring a socially just urban intervention? This, I will attempt to answer by critically analyzing these so called 'strategies' under each dimension.

\subsection{Capacity Building through Developing Human Resources}

As put by Grindle (1997:13), this dimension of capacity building involves "increasing the capacity of individuals to carry out their professional and technical responsibilities", or according to Peltenburg, et al (1996:9), it involves making "optimal use of the total knowledge, skills, creative abilities, talents and attitudes of an organization's workforce". In other words, it involves developing individual capacity through a variety of strategies with the intention of creating a 'trickle down' effect to the organization. Analyzing Grindle's (1997) definition, at first glance, training seems to be the obvious strategy geared towards developing human resources. In contrast, Peltenburg, et al (1996) does not stress the issue of training explicitly but suggests the effective and efficient utilization of employee's skills and competencies within the organization. Here, Peltenburg, et al (1996) makes a link between the human resources and the organizational dimensions of capacity building. I do believe that there is a link between the two because 'expanding the capacity for human agency' (Levy, 
2007) can indeed translate into a strengthened organization in the long run. However, particularly in public sector organizations, it is usually the case that trained employees often find themselves redundant or useless in the sense that the training received may not necessarily be utilized in the organization, for example, in Guyana, employees in the Regional Democratic Council were trained on the use of new computerized record keeping systems and yet record keeping within the organization remained manual.

Further, training employees may not achieve its full effect if review and follow up is absent or if the training process is not monitored and evaluated. A training program that does not consist of these elements may not be very effective in achieving its objective.

Additionally, developing human resources comes at great financial costs and in some instances, trained employees may become more attracted to the private sector because of better incentive packages and greater opportunities for upward mobility. As such, Peltenburg et al (1996) suggest that in addition to training, strategies should be focused on retaining trained employees by motivating employees improved performance through better pay scales, conditions of work and employment, career perspectives, or simply put, exercising good human resource management. This I understand to mean the entire process from recruiting to retiring employees inclusive of all the other functions of human resources management planning, selection, orientation, induction, performance appraisal, promotion, etc. - and ensuring that selection, appraisal, and promotion criteria are just and clearly understood.

\subsection{Capacity Building through Organizational Strengthening}

As stated earlier, there is a clear link between developing human resources and organizational strengthening. However, while human resources development is focused solely on the individual, the latter is a combined focus on the individual, groups and the total organization within which individuals (staff) function (Peltenburg, et al, 1996). It involves strategies at developing the organizational level and the inter-organizational level (networks of organizations). Strategies aimed at strengthening organizations should go hand in hand with strategies aimed at developing the individual. The main reason being is that human resources development will lack its intended impact of retaining and making full use of individual's skills and competencies if the organization is not fully equipped or capable of adapting to change. In other words, it should be a learning organization.

Peltenburg et al (1996) highlighted that strategies should pay close attention to the rules, structures (both formal and informal), culture, and management style. That is, in my words, transforming the organization from a hierarchical top down approach to a more bottom up approach by improving internal communication channels or in the words of Grindle (1997:15), 'restructuring work and authority relationships and introducing better management practices.' It must be noted that strategies intended to strengthen the organization will not be successful if management is not fully committed to it of if the organization does not have a stated realistic mission/vision that is clearly understood by all employees.

Additionally, as mentioned before, organizational strengthening should also look at the inter-organizational level. While Grindle (1997) briefly mentions the issue of decentralization, it is the key reasoning behind strengthening local government organizations. If, for example 
local government is to be transformed into a learning organization, it must be fully supported by and open to participation from the private sector and civil society including NGOs and CBOs for they are the root source of information of the needs and experiences for whom the organization exist to serve.

However, as rightly articulated by Peltenburg etal (1996) and Levy (1998), there is often limited research and unclear methodologies on how these organizations function coupled with the fact that decentralized local governments, particularly in developing countries, although given the autonomy to make decisions, is often not financially and technologically equipped to conduct these strategies. Also, strategies may be limited in the sense that misguided perceptions about capacity building may only be focused on training or on developing the organization at the local level while ignoring other levels and actors in governance, which runs the risk of lacking political commitment and support from central government and other non-governmental organizations.

In addition, if these organizations are not clear on their mandate or have conflicting views on the needs and experiences of the citizenry, how then will these strategies be implemented across the board? This requires inter-organizational information flow and cohesion for the organization will not be able to strengthen its capacity by enhancing its effectiveness and sustainability

\subsection{Capacity Building through Institutional Reform}

The African Youth Alliance (2007) has established a linkage between organizational strengthening and institutional reform by defining institutional capacity building as "the provision of technical or material assistance designed to strengthen one or more elements of organizational effectiveness." However, reforming the institution according to Grindle refers to "altering the rules of the game in which organizations and individuals make decisions and carry out activities" (1997:19) or in keeping with Young's (1990) views on social justice removal of all forms of institutional domination or oppression through reform. These 'rules of the games' to which Grindle refers are policies, the legal systems such as laws guiding public service actions, bye-laws, and regulatory structures or, to my understanding, adhering to the mechanisms of governance or 'good' governance as outlined by the UNDP - rule of law, equity, participation, efficiency, accountability and transparency, responsiveness and consensus orientation.

Strategies aimed at institutional reform include ensuring that policies and programs and methodologies are gender sensitive or include a gender perspective, that they take into consideration the needs of the poor by developing public-private partnerships or forming 'relationships' through inclusion and citizenry participation in institutional structures (Mumtaz, 2001). These strategies, while they appear good in print, may face many constraints, particularly the issue of achieving consensus. If taken wrongly, it can also threaten the 'relationship' among actors. The reason being is that society is very diverse and as such, taking a consensus view of society can have disastrous effects. Rather, taking a view that society exists in 'cooperative conflict' with a state that is 'open to diverse alliances' (Amarta Sen) may serve a better purpose if there is active and fair mediation to deal with 
instances of conflict.

However, a common and recurring question about participation is: Who participates, and what determines whether or not they participate? Is it knowledge, or social and/or political connections? It does not help the situation that DFID believes that "institutions are often creatures of the rich and powerful and commonly discriminate against the poor" (2003: 5). Consequently, if the following is true, then power relations linked to social and political influence can interfere in the capacity building process in favour of the 'rich and powerful.'

Additionally, since interventions in this dimension are usually spearheaded by central government (Peltenburg et al, 1996), countries with 'centralized powers' may have a very weak local government and as such, these strategies may not have a major impact at the local level. As such, there is a need for a change in the operations of local government. This change, among other criteria, should integrate gender sensitive strategies in each element of the strategic intervention process.

\section{A Possible Intervention Strategy: The Web of Institutionalization}

Now that I have analysed some of the necessary strategies that will develop human resources, strengthen organizations and lead to institutional reform, the big question remains: How can these strategies promote socially just intervention in urban governance? It is the assumption of this paper that the strategies of Grindle (1997) and Peltenburg, etal (1996) are focused on government and the public sector. However, in keeping with the argument set forth earlier, these strategies should be also be focused on the other actors in society through an understanding of the elements external to government or the 'external environment' identified by Agenda 21 or according to Mugore (cited in Peltenburg, 1996: 13):

'... profiling the Human Resource Development challenges of 'better cities', one has to analyze and understand Human Resources Management challenges for better cities. To do that one has to understand the general management challenges which face the city of tomorrow, which management challenges must emanate from the needs of its citizens, and the city's perceptions of its role and mandate in meeting these.'

I believe that the best tool to accomplish this task is Levy's 'web of institutionalization', particularly if we are speaking about socially just strategic intervention that results in effective and efficient service delivery (See Appendix 2). Levy's 'web' is best utilized if the strategies under each dimension of capacity building are implemented under each element in the web with a gender sensitive perspective to ensure that the needs of men and women, boys and girls are taken into consideration.

\subsection{The Web and Organizational Strengthening}

In recognition of the link between human resources development and organizational strengthening, the previously discussed strategies for socially just strategic intervention in terms of these dimensions can be focused around the following elements of the web:

- Staff Development in the areas of training, motivation, etc.

- Mainstream Responsibility for incorporating gender into the strategic intervention process 
- Current organization procedures that need to be assessed - organizational culture, etc.

- The Organization's methodology - rules and regulations, structure, etc

- Theory Building

- Applied Research

- The delivery of projects and programs - does it integrate a participatory approach?

This will provide the basis for a detailed analysis of both the internal environment of the organization and those factors prevalent in the external environment that can have an impact on or hinder the successful implementation of the intervention.

\subsection{The Web and Institutional Reform}

Interventions focused on institutional reform should be geared towards the policy sphere of the web. This will provide an avenue for assessing the areas in the policy that need to be addressed based on the following:

- Women's and men's experiences and their reflective interpretation of reality - are they integrated into institutional policies?

- Current and possible future policy and planning - What type of polices are they? Do they incorporate the principles of participation, accountability, transparency, equity, etc?

- The level of political commitment - both local and central government

- The Political structures that are representative of the women's and men's experiences - NGOs, CBOs, and other civil society organizations keeping in mind the issue of leadership

- The resources that are necessary for and those that are available for the intervention

\section{Conclusion}

It can be deduced from this discussion that there is a clear connection between all the dimensions of capacity building with the implication that focusing entirely on one dimension or implementing it at one level or the organization or institution will not be viewed as 'being strategic'.

Additionally, if I am to make a summary of my understanding of the question, it is asking for the strategies that are ensuring that the skills and competencies of individuals within an organization are developed in such a way that they translate to a greatly strengthened organization which motivates and makes use of employees with the sole purpose of producing a strong relationship among actors within and external to the organization by them having an equal voice in decision-making structures.

Or simply put, socially just strategic intervention through capacity building will promote urban governance by 'expanding the room for maneuver' (Levy, 1998) through the removal of 'institutionalized domination and oppression' (Young, 1990) with the intention of creating and maintaining a 'relationship between civil society and the state, (...), the government and 


\section{Macrothink}

Journal of Public Administration and Governance

ISSN 2161-7104 2013, Vol. 3, No. 3

the governed' (McCarney, 1996). This, of course, asks for a participatory approach to government that involves all stakeholders through a process of 'deliberate argument, dialogue, and mediation' (Amarta Sen).

\section{References}

African Youth Alliance (2007), "Institutional Capacity Building", [http://www.ayaonline.org/Strategies/ICB.htm], (accessed 21 April 2007)

DFID, (2003) "Promoting Institutional and Organizational Development", Department for International Development, UK

Grindle, M S (1997), "The good government imperative: Human resources, organizations and institutions" in M S Grindle (ed) in Getting Good Government: Capacity Building in the Public Sectors of Developing Countries, Harvard Institute for International Development

Levy, Caren (1998), 'Institutionalisation of Gender through Participatory Practice" in I Guijt and M K Shah (eds) The Myth of Community: Gender Issues in Participatory Development, Intermediate Technology Publication

Levy, C (2007), "Strategic Intervention in Urban Development", Module BENVUP02, MSc in Urban Development Planning, Development Planning Unit, University College London

Peltenburg, M, etal (1996), "Building Capacity for Better Cities: Concepts and Strategies", Institute for Housing and Urban Development Studies, Netherlands

McCarney, P (1996), “Considerations in the Notion of 'Governance': New Directions for Cities in the Developing World", in P. McCarney (ed) Cities and Governance: New Directions in Latin America, Asia and Africa, Centre for Urban and Community Studies, Toronto

Miller, D (2000), “Citizenship and National Identity,” Cambridge, Polity Press

Mumtaz B, and E Wegelin, (2001) "GUIDING CITIES: The UNDP/UNCHS/WORLD BANK Urban Management Programme", Institute of Housing and Urban Management Studies and the Development Planning Unit, University College London

UN ESCAP, "What is good governance?" [http://www.unescap.org/huset/gg/governance.htm], (accessed 3 January 2007)

Young, I M (1990), 'JUSTICE AND THE POLITICS OF DIFFERENCE”, Princeton University Press, New Jersey 
Appendix 1. Capacity Building for Socially Just Strategic Intervention in Urban Governance

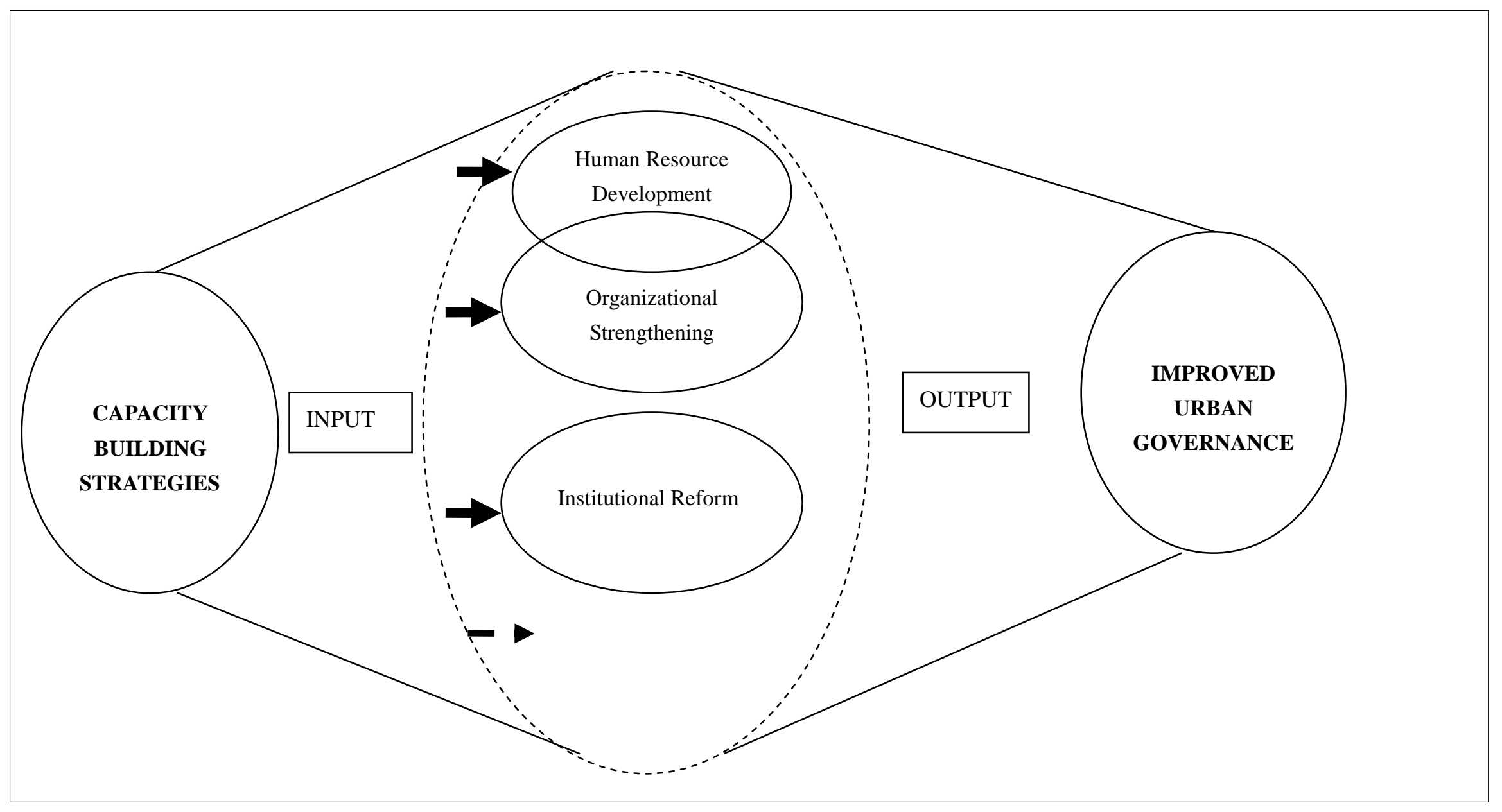


Appendix 2. The Web of Institutionalisation

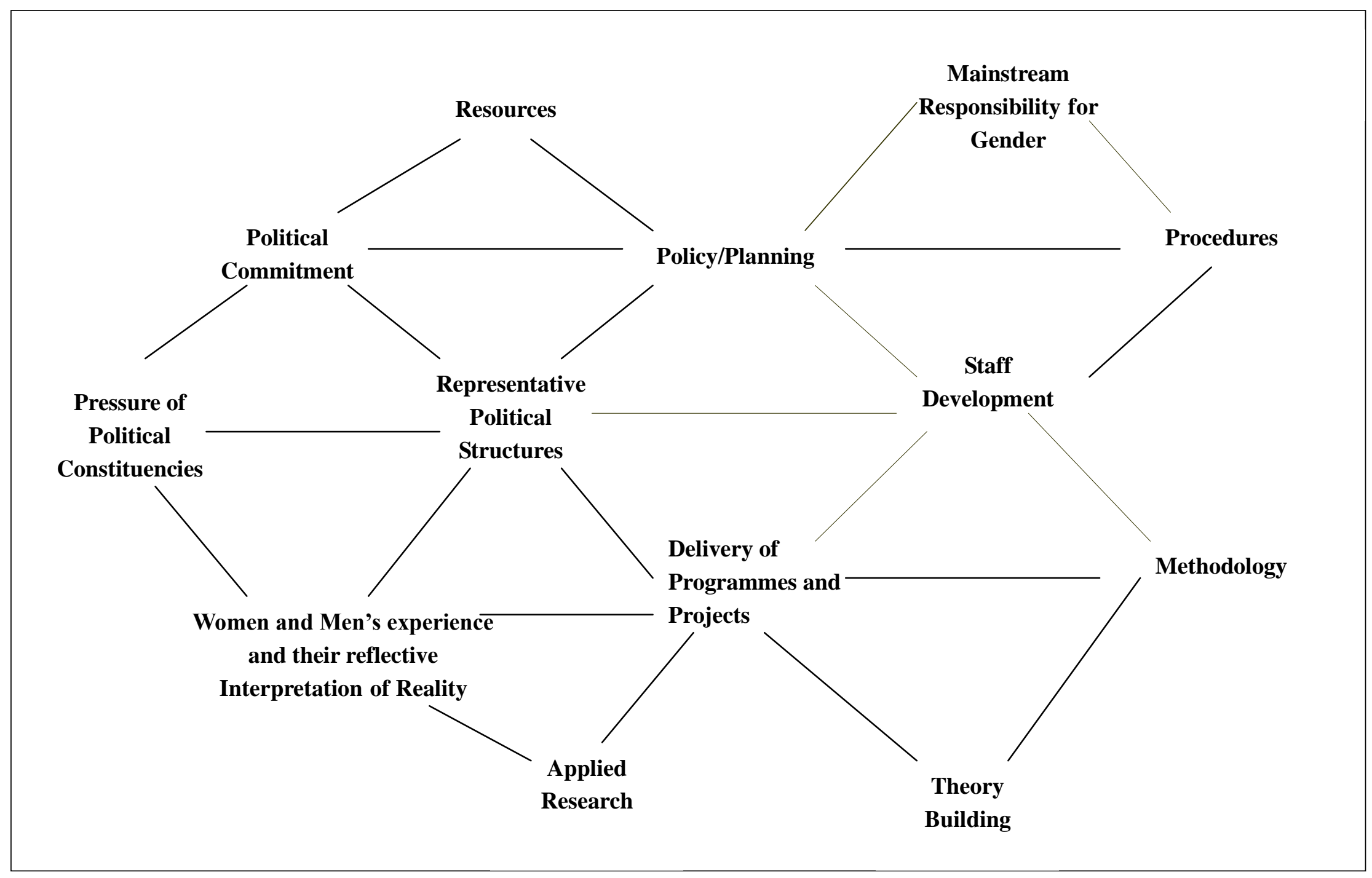




\section{Macrothink}

\section{Copyright Disclaimer}

Copyright reserved by the author.

This article is an open-access article distributed under the terms and conditions of the Creative Commons Attribution license (http://creativecommons.org/licenses/by/3.0/). 